\title{
Identification of domains and measures for assessment battery to examine well-being of spouses of OIF/OEF veterans with PTSD
}

\author{
Jeanne Hayes, PhD, MPA; ${ }^{*}$ Bonnie Wakefield, PhD, RN; ${ }^{2}$ Elena M. Andresen, PhD; ${ }^{3} \mathrm{Jeffrey} \mathrm{Scherrer,} \mathrm{PhD;}^{4-5}$ \\ Laural Traylor, MSW; ${ }^{6}$ Peter Wiegmann, BA; ${ }^{1}$ Thomas Demark, MD; ${ }^{1}$ Cherilyn DeSouza, MD $^{1}$ \\ ${ }^{1}$ Kansas City Department of Veterans Affairs (VA) Medical Center, Kansas City, MO; ${ }^{2}$ Center for Research on Imple- \\ mentation of Innovative Strategies in Practice, Iowa City VA Medical Center, and University of Missouri Sinclair \\ School of Nursing, Iowa City, MO; ${ }^{3}$ Department of Epidemiology and Biostatistics, University of Florida, Gainesville, \\ FL; ${ }^{4}$ St. Louis VA Medical Center, St. Louis, MO; ${ }^{5}$ Department of Psychiatry, Washington University, St. Louis, MO; \\ ${ }^{6}$ Veterans Integrated Service Network 22 Care Coordination Office, Long Beach, CA
}

\begin{abstract}
Family members play an important role in the physical and mental recovery of soldiers returning from Operation Iraqi Freedom (OIF) and Operation Enduring Freedom (OEF). Posttraumatic stress disorder (PTSD) has been associated with strained marital and family relations and parenting difficulties, and many veterans with PTSD experience difficulty finding and maintaining employment. Family members who assist with the veteran's recovery also experience significant strain and may have to leave employment to care for the veteran. Our objective was to identify appropriate assessment measures for examining the well-being of spouses assisting with veterans' recovery and to identify opportunities for supporting veterans' spouses. We used a combination of expert panel input and qualitative methods (focus group interviews) to develop a battery of instruments for use in future research with OIF/OEF family members to examine well-being. Research is needed to elucidate and refine the special needs and issues surrounding PTSD in current and future OIF/OEF veterans and their families. This study provides a first step toward understanding appropriate measures. Expert panel methods and focus group interviews yielded valuable input on the domains and measures that should be included in the assessment battery as well as opportunities for assisting spouses.
\end{abstract}

Key words: assessment, burden, caregivers, expert panel methods, focus groups, OIF/OEF, PTSD, quality of life, rehabilitation, veterans.

\section{INTRODUCTION}

Soldiers deployed as part of Operation Iraqi Freedom (OIF) and Operation Enduring Freedom (OEF) are experiencing a variety of injuries that have long-term implications for their health and well-being and represent significant challenges for the Veterans Health Administration (VHA). American military personnel who have served in Afghanistan and Iraq are experiencing long periods of extreme stress, intense battlefield experiences that pose threats of personal harm and death, taking life, and witnessing or experiencing injuries and death that can have an impact on mental health and emotional wellbeing. Research has shown that combat experience and the stress associated with deployment increase the risk of developing mental health difficulties, including posttraumatic stress disorder (PTSD), depression, and substance

Abbreviations: $\mathrm{OEF}=$ Operation Enduring Freedom, OIF = Operation Iraqi Freedom, PTSD = posttraumatic stress disorder, VA $=$ Department of Veterans Affairs, VHA = Veterans Health Administration.

*Address all correspondence to Jeanne Hayes, PhD, MPA; Kansas City VA Medical Center, 4801 Linwood Blvd, Kansas City, MO 64128; 816-861-4700, ext 57694.

Email: jeanne.hayes@va.gov

DOI:10.1682/JRRD.2009.04.0049 
abuse [1-2]. The estimated lifetime prevalence of PTSD is 30.9 percent for male Vietnam veterans and 26.9 percent for female veterans who served in the Vietnam war.

Elevated rates of PTSD and other Diagnostic and Statistical Manual of Mental Disorders Axis I diagnoses have been reported among OIF/OEF veterans. PTSD is the most common mental health diagnosis among veterans returning from combat and the second most frequent medical diagnosis among veterans who have used VHA healthcare services $[1,3]$. Soldiers who have sustained a combat injury are at particular risk for PTSD [4-9]. Emerging evidence also suggests considerable impact on families of men and women deployed in OIF/OEF. Although widespread recognition is found among the research and clinical communities concerning the hardships that families face in general, research has largely been based on studies of nonmilitary/nonveteran participants, such as older adults, and condition-specific groups, such as those with dementia or stroke [10-12]. Less is known about the physical and emotional stress experienced by spouses of veterans with PTSD (http://www.ncptsd.va. gov/ncmain/ncdocs/fact shts/fs_partners veterans.html, last accessed March 23, 2009) [13].

We describe our efforts to identify domains and measures for inclusion in a battery of assessment tools to examine the well-being of spouses assisting with veterans' care. Domains identified to assess spousal wellbeing include health status, mental health, alcohol and substance abuse, conflict, and marital satisfaction. This study was part of a larger research agenda designed to understand veteran and spousal characteristics and mediating variables that inform spouses' response(s) or appraisal of caregiving and, ultimately, veterans' outcomes. The conceptual framework (Figure) guiding our work, including identification of domains relevant to spousal well-being, is adapted from stress and coping models [14-15]. That providing care to a family member or friend often leads to increased strain and/or burden is widely accepted. The inability to cope effectively with the stressors associated with caregiving can negatively impinge on the spouses' (and veterans') mental and physical health. Changes in care responsibilities and relationships can lead to increased burden and strain that may or may not be successfully managed [16-17].

Recent work in the area of caregiver identity theory suggests that caregivers experience distress in response to a disruption in the identity maintenance process [1819]. The caregiver typically assimilates caregiving into the spousal relationship with little or no distress when the need for caregiving/family assistance is minimal. This process stretches but does not threaten the caregiver's existing identity. However, when the need for assistance requires a fundamental change in spousal roles, threats to a person's existing identity are dramatic and significant effort is required to accommodate the changes. If the need for assistance occurs suddenly or intensifies, the added responsibilities typically surpass the activities that generally characterize the spousal role, and this creates a discrepancy between the spouse's helping actions and how self-identity is perceived in relation to the marriage.

Caregiver identity theory posits that psychological distress (i.e., objective burden, relationship burden, and stress burden) manifests when a discrepancy exists between a caregiver's helping efforts and self-identity [18-19]. When caregiver stress is understood to be caused by a perceived discrepancy between what a caregiver thinks he/she should be doing (based on the caregiver's perception of the marital relationship and selfidentity) and the actual tasks required, effectively targeting resources to reduce or eliminate the sources of distress is possible. Further, spouses' belief in their ability to effectively assist with the veterans' care may also contribute to improved outcomes [20-21]. Spouses who are confident in their ability to assist with and manage the care of their loved one (i.e., higher self-efficacy) have better personal outcomes related to stress and burden and are therefore more likely to have improved mental and physical health outcomes, which could translate into better patient outcomes.

Significant psychological impairment has been associated with assisting with caring for Vietnam veterans with PTSD. Guilt, substance abuse, and vicarious experiencing of the veteran's pain have been reported by spouses of Vietnam-era veterans [22-23]. Families of Vietnam veterans also experience worse mental health outcomes when the veteran has PTSD [24-28]. Spouses of Vietnam veterans with PTSD have more symptoms of depression and other psychological disorders (i.e., anxiety and low self-esteem) than spouses of veterans without PTSD [22,29-30]. Wives of Vietnam-era veterans with PTSD also report significant marital problems, with greater symptom severity associated with increased marital distress, more relationship problems, and greater family dysfunction [24-25, 27-29,31-32]. Further, the potential for intimate partner violence is greater when the veteran has PTSD. For example, 33 percent of veterans with PTSD committed intimate partner violence compared 


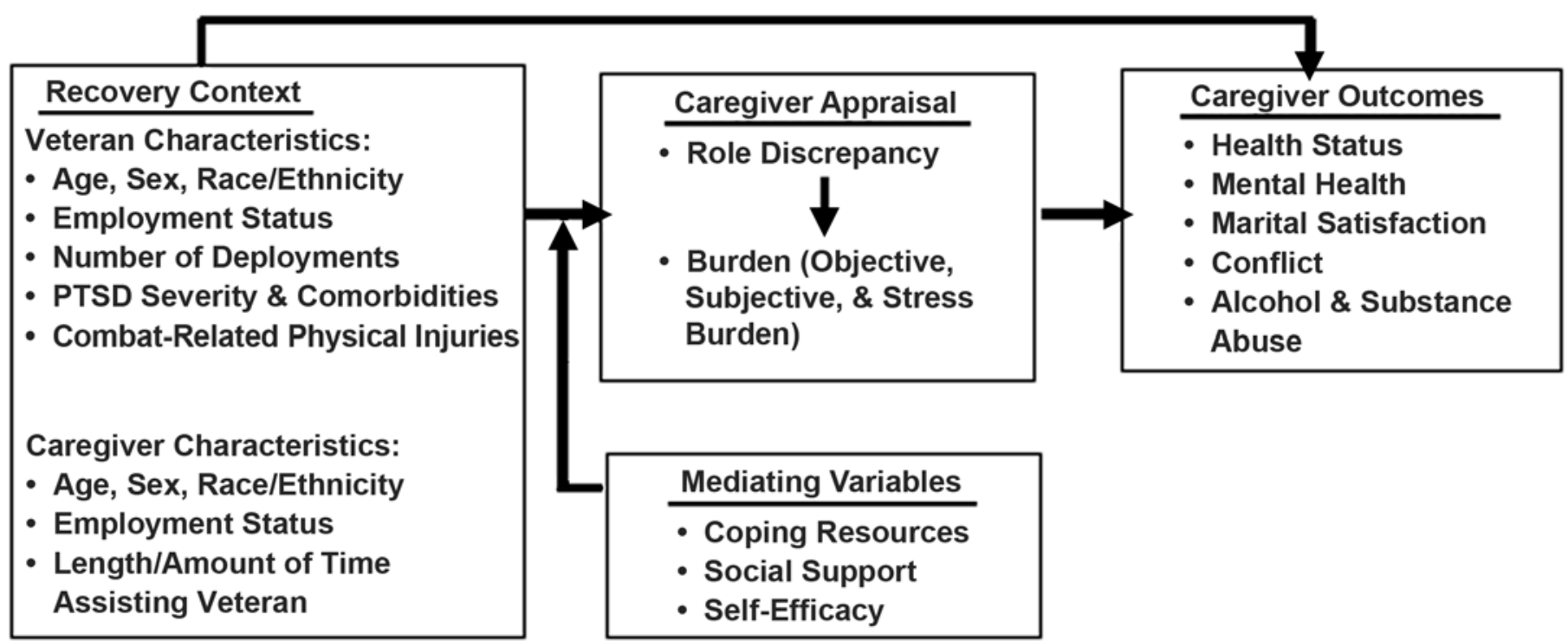

Figure.

Conceptual study framework. PTSD = posttraumatic stress disorder.

with 13.5 percent of veterans who did not have PTSD [11]. Intimate partner violence has been related to poor family functioning and behavioral problems and social dysfunction in children [22,33-34].

Servicemembers and, in turn, their families, may experience difficulty recovering from trauma and require help reintegrating into society [1,4,35-36]. Marital problems, difficulties parenting, strained family relationships, and problems locating and maintaining employment [37] have been reported for OIF/OEF veterans diagnosed with PTSD. PTSD symptoms (intrusions, appearing self-absorbed, emotional numbing, and arousal) can make family and public outings an unpleasant and anxiety-provoking experience for the veteran and his or her family and can cause many spouses and partners to avoid these activities. As a result, spouses and partners of veterans with PTSD often report feeling cut off from friends and family, and many experience significant isolation [31-32,38-40], with limited opportunities to seek healthy outlets and the support of others.

Families play an important role in veterans' recovery and readjustment. How exposure to trauma affects families, in particular spouses and committed partners, is important for the long-term optimal outcomes of OIF/ OEF veterans with PTSD. The Department of Veterans Affairs (VA) has expressed an interest in better understanding the circumstances of OIF/OEF spouses and families and recognizes the need for targeted services to assist and strengthen families. The VA has been providing national trainings for their clinical staff on evidencebased practices for marriage and family counseling. ${ }^{*}$ Further, the VA Mental Health Quality Enhancement Research Initiative is interested in identifying methods to improve family participation in the care of veterans and the development and testing of tools and strategies that promote and support consumer-driven mental health care. The Caregivers and Veterans Omnibus Health Services Act of 2010 requires that the VA document the effects of caregiving on family members and mandates assessment of caregiver needs and resources to more effectively serve our nation's veterans. Documentation of marital partners' experiences provides an opportunity to identify mechanisms for enhancing supporting systems.

\section{METHODS}

We used a combination of qualitative methods (focus group interviews) and expert panel input to identify domains and measures for inclusion in a battery of instruments for use in future research. With guidance from

\footnotetext{
*McCutcheon, Susan. (Office of Mental Health Services, VA, Washington, DC). Email to: Jeanne Hayes (Kansas City VA Medical Center, Kansas City, MO). 2010 Oct 26.
} 
expert panel members, project staff drafted a preliminary list of instruments that was shared with focus group participants for their input on key domains for inclusion in a draft battery of assessment measures. The revised battery was then presented to the expert panel for their approval. A second focus group was convened to make final adjustments to the assessment battery. The recommendations from the expert panel and focus group sessions were incorporated, and project staff reviewed and approved the recommended changes.

\section{Expert Panel Methods}

Expert panel members were recruited based on their status as nationally recognized experts on family and caregiver issues and/or the impact of war and trauma on families (see "Acknowledgments" for a complete listing of participants). We used a two-round consensus-panel method to select and rate the appropriateness of candidate instruments. The first expert panel round was conducted by teleconference and the second round was inperson. Project staff sought the recommendation of expert panel members in conducting an extensive review of published instruments and in compiling instruments for consideration in the assessment battery. Candidate instruments were assessed for appropriateness and feasibility of administration to OIF/OEF spouses. With input from expert panel members, project staff drafted a preliminary list of instruments that was evaluated and refined in an initial round conducted via teleconference. In preparation for the panel teleconference, key candidate instruments were organized by domain and compiled along with documentation describing each scale's development (including reliability and validity), prior uses, and a summary of the project staff's consideration of advantages and limitations. These documents were distributed to the expert panel members prior to the teleconference. Panel members discussed, reviewed, and rated the instruments during the teleconference meeting, helping to elucidate and refine the list of existing measures. During this meeting, a decision was made by consensus vote to either retain each instrument for further discussion or to drop it from consideration. At this point, rating was a simple "include for further discussion" versus "drop from consideration." The panel also made recommendations regarding the need for more information prior to the final review (e.g., from developers or published uses) and identified additional instruments for consideration during the teleconference. Details regarding the list of instruments considered at the first and second panel session and key points regarding the selection of measures, as well as additional considerations, are listed in the Table. The revised battery was shared with veteran spouse focus group participants after the first panel session to ensure that the identified domains and measures captured participants' experiences (see "Focus Group Interviews and Methods" for details). The updated draft was circulated among panel members prior to the 1-day in-person meeting, during which consensus was established concerning the final list of instruments identified for inclusion in the assessment battery. The panel selected measures based on such factors as the psychometric properties of the instrument, clarity of questions, appropriateness for use with the target population, focus group feedback, and familiarity with and ability to access the instrument.

\section{Focus Group Interviews and Methods}

Focus groups represent a type of group interview frequently used to gather input based on participants' experiences about a topic of interest [41]. Focus group research is frequently used to identify information to guide the development of surveys or instruments [42] and can also generate critical knowledge of the language participants use to describe their views [43]. For this reason, lay feedback from persons who will participate in future research is valuable. We sought lay feedback to assist in producing an acceptable battery that would best capture the effect of OIF/OEF veterans' PTSD symptoms on caregivers. Two focus groups were held with spouses of OIF/ OEF veterans to help us identify important domains that should be included in the assessment battery. The second half of each focus group session was devoted to examining the content of the instruments. An interview guide was used to facilitate discussion of the domains of experience relevant to participants. Probes (e.g., "tell me more about that") were used to elicit specific information from participants. Lay preferences were documented, and the need for additional questions was noted. Respondents' answers were regularly repeated, and respondents were asked for confirmation and/or clarification. This provided an excellent opportunity to clarify participants' answers and frequently generated more in-depth responses [44-45].

\section{Procedures and Sample}

Participants included a convenience sample of OIF/OEF spouses assisting with the care of veterans enrolled for treatment for PTSD at a Midwest VA medical center. Participants were given a $\$ 50$ cash honorarium to compensate 
Table.

Domains and instruments considered for assessment battery: Evaluation of instruments for assessment battery.

\begin{tabular}{|c|c|c|c|}
\hline \multirow{2}{*}{ Domains and Measures } & \multicolumn{2}{|c|}{ Panel Action } & \multirow{2}{*}{ Panel Comments } \\
\hline & First Round & Second Round & \\
\hline \multicolumn{4}{|l|}{ Caregiver Characteristics } \\
\hline $\begin{array}{l}\text { National Alliance for Caregiving (NAC) and } \\
\text { the American Association of Retired Persons } \\
\text { (AARP) Survey [2] }\end{array}$ & Retain & Adopted & $\begin{array}{l}\text { Panel stressed need to balance detail and respondent } \\
\text { burden. Panel suggested caregiver be asked about } \\
\text { prior military experience, No. of dependents cared } \\
\text { for regularly, employment status, knowledge of/ } \\
\text { plans to access community \& Internet resources, \& } \\
\text { whether service costs interfered with use. }\end{array}$ \\
\hline \multicolumn{4}{|l|}{ Alcohol and Substance Abuse } \\
\hline CAGE Audit-C (CAGE AUD-C) [3-4] & Retain & Adopted & \multirow[b]{2}{*}{$\begin{array}{l}\text { Panel suggested adapting instruments to assess sub- } \\
\text { stance abuse for women’s drinking levels. Additional } \\
\text { suggestions included assessing “typical” drinking } \\
\text { behavior for past } 12 \text { mo for measure of tolerance \& } \\
\text { asking about prescription use/misuse \& items related } \\
\text { to use of antianxiety \& antidepressant drugs in past } \\
12 \text { mo. }\end{array}$} \\
\hline $\begin{array}{l}\text { Semistructured Assessment for the Genetics of } \\
\text { Alcoholism (SSAGA) [5] }\end{array}$ & Retain & Adopted & \\
\hline
\end{tabular}

\section{Burden}

Caregiver Stain Index (CSI) [6]

Zarit Burden Interview (ZBI) [7]

Tailored Caregiver Assessment and Referral Process: An Evidence Based Model for Effectively Supporting Caregivers (T-CARE) [8]

\section{Conflict (Marital and Parent-Child)}

Conflict Tactics Scale (CTS) (Partner

Version) [9]

CTS (Parent-Child Version) [9]

BRFSS Questionnaire (Module on Domestic Partner Violence) [10]

\section{Coping Resources}

NAC and AARP [2] Survey

Ways of Coping Questionnaire (WOC) [11]

Coping Inventory for Stressful Situations

(CISS) [12]

\section{Health Status}

BRFSS [1]

Short Form Health Survey (SF-8) [13]

$\begin{array}{ll}\text { Retain } & \text { Not Adopted } \\ \text { Retain } & \text { Not Adopted } \\ \text { New Measure } & \text { Adopted }\end{array}$

Retain Adopted

$\begin{array}{ll}- & \text { New } \\ \text { Retain } & \text { Not Adopted }\end{array}$

$\begin{array}{ll}\text { Retain } & \text { Adopted } \\ \text { Retain } & \text { Not Adopted } \\ \text { Retain } & \text { Not Adopted }\end{array}$

Although CSI has been used among older adults, psychometric properties of CSI have not been validated. Further, in addition to yes/no response format, measure was viewed as redundant. T-CARE burden assessment for clinical management was selected for use. It has been used widely among older adults \& has been adapted successfully to other populations.

CTS was considered best measure for assessment of marital and parent conflict. It is widely used in VA $\&$ has solid psychometric properties. Based on input from 2nd focus group, indicating significant parentchild strain, parent-child version of CTS was added.

Panel members felt that measure selection should be decided based on intended use/applicability (prevalence, predictive ability, interventional); e.g., knowledge of coping styles is not easily translated to an intervention. However, knowledge of resources available yields valuable information that can be used to support marital partners. Additionally, it was noted that factor structure of WOC survey has been questioned in recent years \& CISS was perceived as slightly dated.

$\begin{array}{ll}\text { Retain } & \text { Not Adopted } \\ \text { Retain } & \text { Adopted }\end{array}$
Use of BRFSS single-item for self-rated health was considered. Some support for use of single-item measure because of opportunity for comparator (reference) population \& ability to get to measure intensity. Despite these considerations, SF-8 was favored as gold standard among brief health surveys, with strong psychometric properties for each single-item construct assessed. 
Table. (cont)

Domains and instruments considered for assessment battery: Evaluation of instruments for assessment battery.

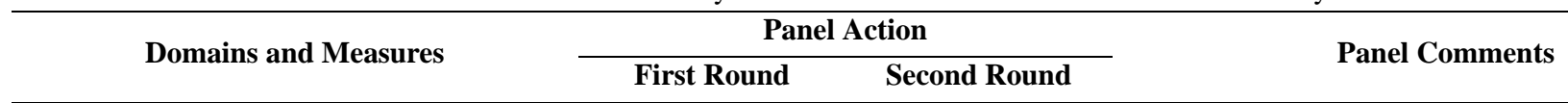

\section{Mental Health (Depression and Suicidal Ideations)}

Center for Epidemiologic Studies Depression Scale-10 (CESD-10) [14]

Physical Health Questionnaire-9 (PHQ-9) [15]

Los Angeles Symptom Checklist (LASC) [16]

SSAGA [5]

$\begin{array}{ll}\text { Retain } & \text { Adopted } \\ \text { Retain } & \text { Not Adopted } \\ \text { Retain } & \text { Not Adopted } \\ \text { Retain } & \text { Not Adopted }\end{array}$

CESD-10 was favored based in part on extensive knowledge of measure, its excellent psychometric properties, \& prior use by team members [4]. Although SSAGA was strongly supported as ideal measure for questions related to suicidal thoughts, it was omitted to reduce respondent burden $\&$ because of IRB concerns related to sensitivity of questions. LASC has been used in VA in recent years to assess spouses' psychiatric symptoms. However, panel noted that it was not developed as measure of partner distress, \& it was dropped from consideration.

\section{Marital Satisfaction}

Dyadic Adjustment Scale (DAS) [17-18]

Relationship Assessment Scale (RAS) [19]

$\begin{array}{ll}\text { Retain } & \text { Adopted } \\ \text { Retain } & \text { Not Adopted } \\ \text { Retain } & \text { Not Adopted }\end{array}$

Personal Assessment of Intimacy in Relationships (PAIR) [20]

Role Discrepancy [21]

$-$

New

New

\section{Self-Efficacy [22]}

\section{Social Support}

Medical Outcomes Study (MOS) Social Support Survey [23]

Social Provisions Scale (SPS) [24]

Retain

Adopted

Retain

Not Adopted

Panel felt that each measure had excellent psychometric properties \& could be understood easily. However, DAS is used widely in VA \& is considered gold standard for assessing marital satisfaction.

Role discrepancy was identified by panel as key construct to be included. Panel selected measure of role discrepancy construct from T-CARE [21].

Panel perceived self-efficacy as crucial to caregiving success \& recommended brief, valid measure for use.

MOS distinguishes receipt of physical health \& emotional support \& was favored by panel \& focus group participants for its brevity \& clarity. Wording on SPS and PRQ were perceived as problematic (negative wording \& neutral "bailout" responses, respectively), which could have negative effect on quality of data. Panel also recommended asking about need for assistance with young children \& additional services.

1. 2000 Behavioral Risk Factor Surveillance System questionnaire [Internet]. Atlanta (GA): Centers for Disease Control and Prevention; 2000. Available from: http://www.cdc.gov/brfss/technical_infodata/surveydata/2000/qcoremod_00.rtf.

2. National Alliance for Caregiving and the American Association of Retired Persons. Caregiving in the U.S. [Internet]. Bethesda (MD): National Alliance for Caregiving; 2005. Available from: http://www.caregiving.org/data/04finalreport.pdf.

3. Bush K, Kivlahan DR, McDonnell MB, Fihn SD, Bradley KA. The AUDIT alcohol consumption questions (AUDIT-C): An effective brief screening test for problem drinking. Ambulatory Care Quality Improvement Project (ACQUIP). Alcohol Use Disorders Identification Test. Arch Intern Med. 1998;158(16):1789-95. [PMID: 9738608]

4. Bradley KA, Bush KR, Epler AJ, Dobie DJ, Davis TM, Sporleder JL, Maynard C, Burman ML, Kivlahan DR. Two brief alcohol-screening tests from the Alcohol Use Disorders Identification Test (AUDIT): Validation in a female Veterans Affairs patient population. Arch Intern Med. 2003;163(7):821-29. [PMID: 12695273] DOI:10.1001/archinte.163.7.821

5. Bucholz KK, Cadoret R, Cloninger C, Dinwiddie SH, Hesselbrock VM, Nurnberger JI Jr, Reich T, Schmidt I, Schuckit MA. A new, semi-structured psychiatric interview for use in genetic linkage studies: A report of the reliability of the SSAGA. J Stud Alcohol. 1994;55(2):149-58. [PMID: 8189735]

6. Robinson BC. Validation of a Caregiver Strain Index. J Gerontol. 1983;38(3):344-48. [PMID: 6841931]

7. Bédard M, Molloy DW, Squire L, Dubois S, Lever JA, O’Donnell M. The Zarit Burden Interview: A new short version and screening version. Gerontologist. 2001;41(5):652-57. [PMID: 11574710]

8. Montgomery RJ, Rowe JM, Kosloski K. Family caregiving. In: Blackburn JA, Dulmus CN, editors. Handbook of gerontology: Evidence-based approaches to theory, practice, and policy. Hoboken (NJ): Wiley; 2007. p. 426-54.

9. Straus MA. Conflict Tactics Scales. In: Jackson NA, editor. Encyclopedia of domestic violence. New York (NY): Routledge; 2007. p. $190-97$. 
Table. (cont)

Domains and instruments considered for assessment battery: Evaluation of instruments for assessment battery.

10. Module on Domestic Partner Violence: 2000 Behavioral Risk Factor Surveillance System questionnaire [Internet]. Atlanta (GA): Centers for Disease Control and Prevention; 2000. Available from: http://www.cdc.gov/brfss/technical_infodata/surveydata/2000/qcoremod_00.rtf.

11. Folkman S, Lazarus RS. Ways of coping questionnaire [Internet]. Menlo Park (CA): MindGarden; 2005. Available from: http://www.mindgarden.com/products/ wayss.htm.

12. Endler NS, Parker JD. Assessment of multidimensional coping: Task, emotion, and avoidance strategies. Psychol Assess. 1994;6(1):50-60. DOI:10.1037/1040-3590.6.1.50

13. Ware JE, Kosinski M, Dewey J, Gandek B. How to score and interpret single-item health status measures: A manual for users of the SF-8 health survey. Lincoln (RI): QualityMetric Inc.; 2001.

14. Andresen EM, Malmgren JE, Carter WB, Patrick DL. Screening for depression in well older adults: Evaluation of a short form of the CES-D (Center for Epidemiologic Studies Depression Scale). Am J Prev Med. 1994;10(2):77-84. [PMID: 8037935]

15. Kroenke K, Spitzer RL, Williams JB. The PHQ-9: Validity of a brief depression severity measure. J Gen Intern Med. 2001;16(9):606-13. [PMID: 11556941] DOI:10.1046/j.1525-1497.2001.016009606.x

16. King LA, King DW, Leskin G, Foy DW. The Los Angeles symptom checklist: A self-report measure of posttraumatic stress disorder. Assessment. 1995;2(1):1-17. DOI:10.1177/1073191195002001001

17. Spanier GB. Measuring dyadic adjustment: New scales for assessing the quality of marriage and similar dyads. J Marriage Fam. 1976;38(1):15-28. DOI:10.2307/350547

18. Busby DM, Christensen C, Crane DR, Larson JH. A revision of the dyadic adjustment scale for use with distressed and nondistressed couples: Construct hierarchy and multidimensional scales. J Marital Fam Ther. 1995;21(3):289-308. DOI:10.1111/j.1752-0606.1995.tb00163.x

19. Hendrick SS. A generic measure of relationship satisfaction. J Marriage Fam. 1998;50(1):93-98. DOI:10.2307/352430

20. Schaefer MT, Olson DH. Assessing intimacy: The pair inventory. J Marital Fam Ther. 1981;7(1):47-60. DOI:10.1111/j.1752-0606.1981.tb01351.x

21. Montgomery R, Kwak J. TCARE: Tailored caregiver assessment and referral. Am J Nurs. 2008;108(9 Suppl):54-57. [PMID: 18797229]

22. Bandura A. Self-efficacy: The exercise of control. New York: W. H. Freeman; 1997. 604 p.

23. Sherbourne CD, Stewart AL. The MOS social support survey. Soc Sci Med. 1991;32(6):705-14. [PMID: 2035047] DOI:10.1016/0277-9536(91)90150-B

24. Weiss RS. The provisions of social relationships. In: Rubin Z, editor. Doing unto others. Englewood Cliffs (NJ): Prentice-Hall; 1974. p. 17-26.

25. Weinert C. Measuring social support: PRQ2000. In: Strickland O, DiIorio C, editors. Measurement of nursing outcomes: Self-care and coping. Vol. 3. New York (NY): Springer Pub Co; 2003. p. 161-72.

IRB = institutional review board, VA = Department of Veterans Affairs.

them for their time. Each focus group interview lasted about 2 hours. Participants were recruited with the assistance of a mental health clinician in a Midwest VA healthcare facility. The clinician informed the veteran about the study during a regularly scheduled appointment or via telephone and asked about the availability of a partner willing to participate in a focus group session. If the spouse was receptive to participation or wanted to know more about the study, contact information was shared with the project team. The principle investigator or project coordinator then telephoned spouses to further explain the study and inquire about their willingness to participate in group interviews.

\section{Analysis of Focus Group Data}

The audio narrative interview data were recorded, transcribed verbatim, and verified for accuracy and completeness by project staff. Two coders jointly established the coding scheme and assessed variations within and across themes and categories. We paid special attention to the general setting, timing, and arrangement of events; participants and their roles; and events that stood out as significant or were minimized by caregivers [46-47]. Ini- tial codes were applied to larger sets of data and used to generate themes and categories. The information obtained from the focus-group research played a critical role in cross-validation of the candidate instruments and expert panel feedback.

\section{RESULTS: INTERVIEWS WITH OIF/OEF SPOUSES}

Seven women participated in the focus group interviews. All were married or engaged to be married to an OIF/OEF veteran (although one interviewee was not married but engaged, throughout this article we refer to all the veterans and women as "spouse(s)" or "husband" and "wife"). Interviewees had a mean age of 29.7 years (range 24-34), and the veterans they cared for had a mean age of 34.6 years (range 26-48). Three of the seven women interviewed had children in the home, and four of the seven women interviewed worked full-time. The length of time since deployment of their veteran partner ranged from 6 months to 5 years. Important themes were discovered and are discussed here. 


\section{Participant Characteristics}

All of the women we interviewed reported significant financial strain as a result of their spouse's PTSD. In each family, only one spouse was employed. Four women worked full-time because the veteran was unable to work as a result of the severity of the PTSD. Further, three women agreed not to work as a condition of the veteran's acceptance into an intensive treatment program for PTSD. Gambling also led to financial difficulties. Focus group participants (and veterans) reported having problems with their employers as a result of the veteran's PTSD, including time away from work and time spent talking to and coaching the veteran while at work. Women who were employed worried about losing their jobs because of the amount of time they spent during the work day "talking the veteran down," speaking to the veteran's doctor, or accompanying him to appointments. One woman, who described herself as "on call to help him cope with things," and consequently "very stressed," indicated that she had chosen to give up her job as she could not provide the level of support her husband needed, work full-time, and deal with her own stress.

I was employed and I actually lost my job about 3 months ago. It was . . . something's got to give. Either work's got to give or home's got to give. I'm not giving up on home. I'd rather be happy and broke than to have all the money in the world and hate everything about my life. I decided it's not worth it. So, I quit working and that makes it tougher to not have family close by.

-Interviewee

In some cases, the veteran lost his job for taking time off to deal with PTSD symptoms, even though he should be protected by the Family Medical Leave Act. Other participants reported that the veteran had stabilized enough to secure and keep employment. However, in each case, the veteran was not working in his area of training and instead had accepted an entry level, lowerpaying job that entailed fewer responsibilities and less stress.

\section{Burden}

Focus group data indicate that military families affected by PTSD are likely to report significant financial burden. All of the participants we interviewed were noticeably distressed and expressed severe strain/burden because of the demands placed on them. Most of the women we spoke to described their work to help diffuse whatever situation arose and to prevent potential crises as "constant, a 24/7 job, or on call around the clock." Focus group participants focused on the difficulty of working, coupled with taking care of the home and children, while also supporting the veteran "around the clock," by helping him to sort out his feelings.

I deal with a lot of stress [at work] all the time and then if there is an issue at home, he's not feeling good, he's sick or something crazy has happened, then I have to go home and destress the situation. I have to do the laundry, I have to cook, I have to clean. Whatever needs to be done ... I've been at work and I come home and try to get things done so that I can go to sleep, get things done, whatever.

- Interviewee

Spouses reported devoting countless hours to helping the veteran cope with anxiety, fear, irritability, fits of anger and rage, and interpersonal relations. This included helping the veteran sort out problems with his family of origin and relations with coworkers and superiors if employed. They also reported spending a significant part of each day encouraging the veteran to "take the medications prescribed, eat, shower, and clean up."

The intense demands placed on spouses created significant strain and worry. One woman worried about losing her job because of the amount of time she devoted to helping the spouse each day.

He calls me at least three times a day while I'm at work. It gets really bad because I work in a busy office. I'm a busy professional ... I can't be taking his phone calls ... I can't be talking on the phone all day. So I'm constantly worried that I'm going to get in trouble because I'm on the phone with him about something. And most of the time, it's nothing. Just that, either he wants to hear my voice, he wants to know that I'm okay, or he wants to know when I'm coming home.

\section{-Interviewee}

Although time since deployment was a factor in the veterans' ability to readjust and the demands placed on the interviewee were varied, all of the women we talked to continued to experience significant strain. However, time since deployment seemed to make a difference in terms of the number and frequency of daily crises. Participants whose spouse had returned 3 or more years earlier 
reported greater stability but continued to experience considerable burden.

Women experienced significant care demands and consequently had very little, if any, time for relaxation or time to themselves. They described one of their biggest challenges as finding personal time: "There's no me time.” Another woman further explained, "My biggest challenge is just being my own person.” Like other participants we interviewed, she found it very hard to retain a sense of self when she spent all her time doing things and caring for others.

My best friend died recently and it was like the worst time of my entire life . . . other than stuff dealing with my husband ... she was everything to me outside of my family. She's been gone several months and I haven't cried because I don't get time by myself to deal with how I feel. I'm always worried about what everybody else is doing. So I would say that's probably the biggest thing, keeping me as an individual person, rather than just being a mom and wife.

—Interviewee

\section{Health Status/Mental Health}

The impact of the veterans' emotional trauma on their spouses' physical and mental health was documented in expert panel discussions and focus group interviews. The majority of the women interviewed described very difficult circumstances at home after their husband's return. All the women indicated that besides PTSD, many veterans experienced depression, anxiety, and sleep disturbance in addition to a broad range of medical conditions. Veterans' mental state and poor physical health affected spouses' health negatively. Participants reported their own significant mental and physical strain in response to caregiving, and some women reported that they were also seeking counseling and taking psychoactive medications for depression and/or anxiety.

\section{Alcohol and Substance Abuse}

Participants were aware that many veterans and their spouses develop problems with prescription medications, use of alcohol and illicit drugs, and/or gambling as a means of coping with stress or problems when readjusting to civilian life. These were generally not reported to be issues for the women we interviewed. However, the veterans' increased consumption of alcohol and cigarettes was a problem most women mentioned. When asked whether alcohol consumption and use of drugs (prescription and illicit) by marital partners should be explored further, all participants agreed that it was an important topic and many reported that they knew of other spouses (and veterans) who had developed problems with drugs and/or alcohol.

\section{Conflict (Marital and Parental)}

The effect of the veterans' emotional lability and the quality of marital relations was considered by the expert panel and was confirmed as an important issue by focus group participants. None of the women we interviewed indicated that physical abuse was a problem. However, all the women we interviewed described the spouse as very emotional. Husbands were "volatile" and "subject to rage.” One woman explained, "He gets very, very angry, very easily." Given veterans' fragile emotional state and emotional lability, many women were concerned about their husband's "preoccupation with weapons," especially the desire to take a weapon along when going out in public. For example, most of the women we spoke to indicated that their husband could easily be enraged if he perceived that another driver had been aggressive toward him in any way. Some women feared that the situation could escalate and the husband might use his weapon on another driver if he had it in his possession during an altercation. All the women but one indicated that they pressed the veteran to leave the weapons at home when they went out. One woman explained her concerns-

I'm sitting in the passenger seat, this guy comes up and pulls in front but doesn't make room and almost hits the side of the car where I'm sitting and my husband gets mad, threatening. He wants the guy to pull off to the side of the road so that he can take care of the issue ... He does carry a knife with him wherever he goes. No gun, because I won't allow him to have a gun because right now he explodes so fast that ... I know that he's responsible with guns, but it's just not something I want him to carry around, period.

\section{- Interviewee}

Several women also commented that soon after returning from combat, veterans were sleeping with weapons. Participants discouraged this behavior and encouraged veterans to "put the guns away" so that they were not easily accessible to the veteran or any children in the home. 
Participants also reported that veterans experienced problems with hypervigilance and paranoia. All but one woman described the veteran as hyperreactive to environmental stimuli of any sort and hypervigilant. In some instances, this resulted in the wife being punched if the veteran was not forewarned of her presence. Hypervigilance also caused problems for some veterans and their wives in public settings. Participants also talked about the husband's fear of being in public or crowded places after having been exposed to combat, bombings, and enemy attacks.

We used to go into Target, [but] he can't be around crowds ... he was on his knees and he was hollering with his hands over his ears, saying something like, "Get me out of here," and kids were coming around looking at him, and he was just screaming, like, a fit of rage.

\section{-Interviewee}

Veterans seldom wanted to go anywhere, and behaviors like these made it difficult for their wives to feel comfortable going out in public. Outings were generally limited to visits with family if they lived nearby, going to the store, or hanging out with military friends and their families. Many women reported feeling relatively isolated as a result and also misunderstood by and disconnected from the general public.

We also asked participants about how their husband's PTSD affected children in the home. Three of the seven women we interviewed had young children. Women with children were concerned that the husband's depression, anger, and preoccupation with his own issues negatively affected the children. One woman explained that her children had worried about their father a lot while he was away. After returning home, though, the veteran had "very little patience and no interest in the children." The husband seldom played with the children and yelled at them a lot. This suggests that the veteran's own children could be a trigger for the PTSD symptoms, especially if the veteran saw children injured or killed while deployed. As a result, the wives felt very sad for the children.

My husband has absolutely no patience. Before, I was the one who was always yelling at everybody. Now he's like that. He just had oral surgery and our son told my mom that he was glad that his Dad had surgery so now he can't yell at him all the time.
The women noted that boys in particular idolized their fathers, and some veterans treated their sons more harshly upon returning from deployment, treating them like little soldiers and thereby retaining a military mindset after returning home. When the relationship assumed a harsher tone, boys were deeply hurt.

Oh, my husband totally drills him. "You gotta do it this way!" Constantly since the day he got back. I mean, I feel sorry for our son. He’s just on top of him and will not let up, and my poor son is like, "I can’t do anything right.” But, you know, I think that's the only reason why we fight ... “Well, he's not your soldier, you know? He's your son.”

-Interviewee

Women also experienced problems with children mirroring the veteran's behavior. The veteran's anger, impulsivity, and depression have been shown to affect children [22,30,32,34]. Boys have been shown to adopt the maladaptive traits of their fathers, but the literature is inconclusive $[32,48]$. One woman talks about her struggle with her son mirroring his father's depression and memory problems.

If Daddy feels like taking the gun out and shooting somebody today, he wants to do it, too. I mean, he does everything my husband does. My husband can't remember things because of the PTSD and traumatic brain injury . . . he can't remember what he did 5 minutes ago. You ask the child something, "I don't know. I don't remember.” It’s a struggle.

\section{—Interviewee}

The symposium of experts convened by the Center for the Study of Traumatic Stress reported that children are often not adequately prepared to cope with their parent's injury and have varied reactions to the changes in their parent and their emotional well-being is frequently affected [49]. Further, parents need guidance in knowing how much to tell children about the injuries sustained by the veteran.

Children in military families often experience significant uncertainty and fear associated with having a parent in combat. They often ask, "Is Mommy/Daddy okay? When is she/he coming home?" or "Is my Mother/Father going to die?” Once the absent parent returns, spouses face competing demands for their attention. Many spouses work, take care of the children, and assist with 
the veteran's recovery. Given these challenges, it may be difficult for a child to be a kid. Parents, the well spouse in particular, may struggle to maintain the integrity of the family [32]. They also experience measurable problems with family adjustment [22]. Several women talked about the difficulty of meeting this challenge. One woman told us-

I would say my biggest challenge probably is helping us to function as a family, with a Mom and a Dad, and the kids who can rely on the Mom and the Dad.

\section{-Interviewee}

Another woman shared this concern and talked about the difficulty of getting her husband to step up and "be there" for the kids.

All I do is take care of people. I go to work, I come home, I cook dinner, I do laundry, I get the school bags ready for the next day ... so my biggest challenge is to condition my children that when they go to their Dad and say, "Daddy, I need ....," he needs to fill in the blank. Whatever they need, they need to know that he's going to respond and take care of them.

\section{- Interviewee}

Focus group and panel participants strongly recommended that future work include an examination of the effect of the veteran's trauma on children. Accordingly, the parent-child version of the Conflict Tactics Scale was added to the proposed assessment battery. Children who grow up in military families are more likely than those raised in nonmilitary families to enlist in the armed services. The health of military families, including spouses and children, is of vital importance to the health of our armed services and national security.

\section{Marital Satisfaction}

Within the context of supporting the spouse in his struggle to recover mentally and physically, women described significant changes in marital relations and some women openly described their husband as a changed man. One woman talks about some of the behavioral changes she has identified in her husband, including fits of rage and gambling and about her perception of him as a changed person.

He's been training our dog to do certain different things that he's never done before-to kill, to attack. He loves to go to the casino and blow money - he never has done that before...Super Bowl weekend, he tore up his room-broke windows in the house, he turned over a TV. He's just not the man that I married. He came back as a body, but it's not him.

\section{—Interviewee}

\section{Role Discrepancy and Self-Efficacy}

Other participants similarly perceived the spouse as a changed person. Sometimes the veteran had been passionate about a particular subject or activity before his deployment but lost all interest after returning. Other times, the veteran was described as no longer interested in seeing friends with whom he had been close before the deployment, suggesting depression and emotional numbing in addition to the PTSD. In some cases, the veteran was disinterested in or angry toward the children. Participants also felt as though the nature of their relationship had changed, with multiple women describing themselves as "parenting" or "babysitting" the spouse. One woman explained, "It just feels like I parent him, in a nutshell."

The women in our study were admittedly strongly committed to the veteran and played a critical role in the veteran's recovery. Without the support of their marital partner, veterans' chances of recovering from PTSD and other war-related traumas may be minimized. Still, women questioned their ability to provide a lifetime of support and wondered how long they could continue given the intensity of their husbands' needs. The need for education and training to enhance skills sets in dealing with PTSD and related issues was also noted.

\section{Social Support}

The intense demands experienced by participants, coupled with veterans' discomfort with public settings and disinterest in associating with others, placed significant restrictions on the women we interviewed. Further, veterans' families were seldom perceived as supportive or understanding of the veterans' or spouses' needs. Women generally described their own families as supportive but some lived at a distance from their own families. Even when families were close, veterans had a hard time feeling comfortable around their in-laws, and tended to "isolate" themselves from them. Participants had very little "me time," and because of the intense demands placed on them had no time to develop a support network or maintain prior friendships. Participants talked about 
the difficulty of maintaining friendships and relationships with family, given the care demands and the changes in their husbands. One woman explained-

I'm just always going to everybody else's doctor appointment. I don't have time to do anything for myself. When he was gone, I was like a single Mom. You know, I did tons of stuff with my single friends, but now that he's home and especially with all his care, a lot of them, they didn't know him before ... they're not seeing the real him. You know? It's just hard. Like one person who was a good friend, I think she got her feelings hurt. I didn't have time to call her anymore, and she doesn't talk to me anymore and I think it's because I didn't have time to call her. I didn't have time to call anybody.

\section{- Interviewee}

Women felt that in general there is a lack of appreciation for the sacrifice that soldiers and their families make: "People don't understand the sacrifice that not only he made, but that we made too. And that our kids made it." Participants similarly expressed concern that others seldom understand the special needs and circumstances of military families. The Center for the Study of Traumatic Stress similarly reported that many spouses of injured veterans feel overlooked [49]. Addressing the veteran's physical health is the primary focus, and families often do not receive the attention they need to help them cope with the changes they are experiencing as a result of the veteran's injuries. Significant anxiety and fear are present building up to and during the deployment. Once the veteran returns home and problems arise, support is available to the veteran, but not enough support is available for the spouse or children. Several women who participated in our focus group interviews had no one in their local area whom they could talk to or turn to for support or help with the issues they were facing. They also felt ignored by the spouse's care providers, whom they spoke with frequently on the veterans' behalf both at the Department of Defense and the VA: "Nobody has ever asked me anything. Like, 'How are you doing?'” As was mentioned by the Center for the Study of Traumatic Stress workgroup symposium cited previously, these problems owe their existence to policy shortcomings that focus solely on veterans as the loci for their health and life problems. With any combat injury, especially PTSD, there can be serious challenges to family integrity and stability.
Expert panel methods and focus group interviews yielded valuable input regarding the domains and measures to be included in the assessment battery (Table). Use of these methods resulted in the selection of valid, reliable assessment tools that can be adapted and included in an assessment battery to be administered in future research examining the effect of assisting in veterans' care. The domains discussed at the first and second panel session and the recommended assessment instruments to be adopted for documenting caregiver well-being and unmet need are provided in the Table.

\section{DISCUSSION}

Our efforts to identify key domains and select instruments for future administration to a nationally representative sample of OIF/OEF spouses were greatly aided by the guidance we received from a team of experts. We also received much-needed feedback from veterans' spouses. The focus group interviews provided us the opportunity to explore the effects of current theatre veterans' PTSD on the spouse and family unit. Our qualitative findings substantiated prior research on Vietnam veterans demonstrating that PTSD can have a significant effect on spouses and partners [22,30-32,39,50].

Feedback from spouses validated the study team's initial set of domains, specifically quality of life, depression, alcohol and substance abuse, the potential for suicide in this population of women, social support, coping resources, the quality of the marital relationship, intimate partner violence, spousal burden, and role reversal. Participants' input was also crucial to selecting the best instruments for the assessment battery and resulted in the addition of one domain to assess parent-child relations. Participants strongly recommended that an instrument to assess veteran-child relations be included. The negative effects of PTSD on children have been reported previously [22,30,34]. We also found that children are negatively affected by the veteran's emotional trauma, with boys in particular experiencing stressful, negative relations with their fathers and also mirroring their fathers' maladaptive behaviors [32,34]. Further, while misuse of alcohol and substance abuse (prescription medications, nonprescription medications, and street drugs) was reportedly not a problem for the women we interviewed, they were aware of problems among military families coping with PTSD and other adjustment disorders. Jordan 
et al. found that few women reported personal alcohol/ drug use, despite it being a notable concern for the veterans themselves [22]. However, caregiver burden has been correlated with increased distress, dysphoria, and poorer overall psychological and physical health [32]. Further, female partners of Vietnam war veterans were significantly more likely to report feeling that they were on the verge of a nervous breakdown; the possibility of using or misusing alcohol and drugs to alleviate anxiety and other distressing symptoms may well be a real concern for this group. Expert panel members in clinical practice expressed concern for spouses in this regard, based on their knowledge of veterans' (and partners') experiences with these issues.

The women we interviewed experienced considerable difficulty handling all of the demands placed on them (i.e., wife, care partner, employee, mother), experienced decreased quality of life, reported significant burden, experienced marital strain, and some reported depression and anxiety. Qualitative findings also provided a glimpse of the many contributions and trials spouses of current theater veterans with PTSD experience on a day-to-day basis and opportunities for enhancing support to families. Conversations with treating clinicians as well as our own focus group data suggest that many veterans experienced strained relations with their family of origin as a child or young adult and, consequently, entered the service searching for a better life. When they developed mental health issues, relations with the family of origin often deteriorated even further. We found that the veteran is often hurt deeply by family members' reactions to his diagnosis and the problems he experiences in his recovery. Further, the spouse who is assisting in the veteran's recovery typically finds very little support from her in-laws. In addition, because the spouse is so immersed in work and family, and given the veterans' need for assistance, little time is left to nurture existing relationships or develop new support systems.

Identifying barriers to care (specific to the VA) for OIF/OEF veterans, spouses, and families will be a component of future research. Additionally, as recommended by the expert panel, future testing should include an examination of measurement characteristics. Rasch analysis (i.e., item response theory) and classic test theory strategies (i.e., retest reliability) will be used as complementary strategies for convergence on selection of best measures in a follow-up study [51-53]. Importantly, not all of the instruments selected for the battery have been subjected to comprehensive testing or would be applied with a new population (spouses of OIF/OEF veterans). The resulting list of instruments may also need further refinement for specific research. Additional detail on relationships in the family, for example with children, might also be needed depending on the research objectives.

Our research results have some limitations. We were limited by the small sample of women we interviewed from a single VA medical center and the cross-sectional snapshot of their lives. While a sample of about 20 is generally believed to be sufficient to achieve theoretical saturation [54], a qualitative approach used to gauge when sufficient data have been obtained to adequately answer the research questions, our sample size was restricted to no more than nine spouses in the absence of prior approval by the Office of Budget and Management, a lengthy process that would have prohibited timely completion of our 1-year project.

Our findings, while preliminary, point to the need for additional research to document unmet needs and to identify ways to better serve this population with targeted, specific interventions. As the VHA contemplates expanded outreach and mental health services for families, it is imperative to examine the specific needs and services that could make a difference in the lives of current and future theatre families. Because families play a key role in veterans' recovery and readjustment, information on how the servicemembers' exposure to trauma affects families, especially spouses assisting with the veterans care, is needed. While existing research can provide insight as to the difficulties that OIF/OEF spouses may face, troop characteristics and the combat experiences of those deployed suggest the need for focused efforts to assist the families of America's newest veterans. This project provides a critical first step by adapting existing measures to assess the effect of servicemembers' exposure to combat stressors and diagnosis of PTSD on marital partners. The generalizability of our findings is limited by the fact that all focus group members were spouses and not other family members (e.g., adult children, parents, siblings). Although we elected to choose valid tested measures because of convenience, measure development to assess the unique needs and difficulties of this population should be considered in future efforts.

\section{CONCLUSIONS}

Expert panel and qualitative methods are effective techniques for identifying focused assessment measures 
that may identify factors that contribute to marital partner's well-being and identify unmet needs. Focus group interviews yielded valuable input on the domains of experience and key questions that should be included in an assessment battery designed to assess well-being and areas where assistance is needed. Additional research is needed to elucidate and refine the special needs and issues surrounding PTSD in current and future OIF/OEF veterans and their families.

\section{ACKNOWLEDGMENTS}

\author{
Author Contributions: \\ Study concept and design: J. Hayes, B. Wakefield, E. M. Andresen. \\ Acquisition of data: C. DeSouza, T. Demark. \\ Analysis and interpretation of data: J. Hayes, P. Weigmann. \\ Drafting of manuscript: J. Hayes. \\ Critical revision of manuscript for important intellectual content: \\ B. Wakefield, J. Scherrer, E. M. Andresen, L. Traylor. \\ Obtained funding: J. Hayes, B. Wakefield. \\ Administrative, technical, or material support: P. Weigmann. \\ Study supervision: J. Hayes, B. Wakefield. \\ Financial Disclosures: The authors have declared that no competing \\ interests exist.
}

Funding/Support: This material was based on work supported by the VA Health Services Research and Development Service (grant SHP 08-170) through an award to Drs. Jeanne Hayes (Kansas City VA Medical Center) and Bonnie Wakefield (Harry S. Truman Memorial Veterans' Hospital).

Additional Contributions: We extend our thanks to the family caregivers who generously contributed their time and effort by participating in the interviews conducted for this study. The qualitative findings have been a valuable component of our work and will inform future efforts. We hope that we have honored your efforts to support America's veterans who are struggling to recover from PTSD.

We would also like to acknowledge the significant contributions of the panel members, whose willingness to devote their time and expert knowledge was instrumental to our efforts: Rhonda J. V. Montgomery, $\mathrm{PhD}$, Helen Bader Endowed Chair of Applied Gerontology \& Professor of Sociology, University of Wisconsin-Milwaukee; Keith Armstrong, MSW, Director of Mental Health Social Work, San Francisco VA Medical Center; Ronda Talley, PhD, MPH, Division of Human Development and Disability, National Center on Birth, Defects and Developmental Disabilities, Centers for Disease Control and Prevention; Michelle Sherman, PhD, Director, Family Mental Health Program, Oklahoma City VA Medical Center; Gail Hunt, MA, President \& Chief Executive Officer, National Alliance for Caregiving.

Institutional Review: The complete research protocol for this study was approved by the VA Subcommittee on Clinical Investigation at the Kansas City VA Medical Center. A member of the study team contacted each veteran to discuss the study, determine willingness to participate, and determine the availability of a spouse who was actively assisting in the veteran's care. Informed consent was obtained from each focus group member prior to the group interview.
Participant Follow-Up: The authors do not plan to inform participants of the publication of this study.

\section{REFERENCES}

1. VHA Office of Public Health and Environmental Hazards. Analysis of VA health care utilization among U.S. Southwest Asian war veterans. Washington (DC): Department of Veterans Affairs; 2006.

2. Kang HK, Natelson BH, Mahan CM, Lee KY, Murphy FM. Posttraumatic stress disorder and chronic fatigue syndrome-like illness among Gulf War veterans: A populationbased survey of 30,000 veterans. Am J Epidemiol. 2003; 157(2):141-48. [PMID: 12522021] DOI:10.1093/aje/kwf187

3. Department of Veterans Affairs: Mental Health. Fact Sheet: PTSD [Internet]. Washington (DC): Department of Veterans Affairs; 2010 [cited 2010 Oct 26]. Available from: http://www.mentalhealth.va.gov/PTSD.asp.

4. Hoge CW, Castro CA, Messer SC, McGurk D, Cotting DI, Koffman RL. Combat duty in Iraq and Afghanistan, mental health problems, and barriers to care. N Engl J Med. 2004; 351(1):13-22. [PMID: 15229303] DOI:10.1056/NEJMoa040603

5. Martz E. Do post-traumatic stress symptoms predict reactions of adaptation to disability after a sudden-onset spinal cord injury? Int J Rehabil Res. 2004;27(3):185-94.

[PMID: 15319688] DOI:10.1097/00004356-200409000-00003

6. Martz E. Associations and predictors of posttraumatic stress levels according to person-related, disability-related, and trauma-related variables among individuals with spinal cord injuries. Rehabil Psychol. 2005;50(2):149-57. DOI:10.1037/0090-5550.50.2.149

7. O’Donnell ML, Creamer M, Pattison P. Posttraumatic stress disorder and depression following trauma: Understanding comorbidity. Am J Psychiatry. 2004;161(8):1390-96. [PMID: 15285964] DOI:10.1176/appi.ajp.161.8.1390

8. Radnitz CL, Hsu L, Willard J, Perez-Strumolo L, Festa J, Lillian LB, Walczak S, Tirch DD, Schlein IS, Binks M, Broderick CP. Posttraumatic stress disorder in veterans with spinal cord injury: Trauma-related risk factors. J Trauma Stress. 1998;11(3):505-20. [PMID: 9690190] DOI:10.1023/A:1024404729251

9. Radnitz CL, Schlein IS, Walczak S, Broderick CP, Binks $\mathrm{M}$, Tirch DD. The prevalence of posttraumatic stress disorder in veterans with spinal cord injury. Sci Psychosoc Process. 1995;8:145-49.

10. Hannum Rose J, Bowman KF, O’Toole EE, Abbott K, Love TE, Thomas C, Dawson NV. Caregiver objective burden and assessments of patient-centered, family-focused 
care for frail elderly veterans. Gerontologist. 2007;47(1): 21-33. [PMID: 17327537]

11. Stewart M, Barnfather A, Neufeld A, Warren S, Letourneau $\mathrm{N}$, Liu L. Accessible support for family caregivers of seniors with chronic conditions: From isolation to inclusion. Can J Aging. 2006;25(2):179-92. [PMID: 16821200] DOI:10.1353/cja.2006.0041

12. Vickrey BG, Mittman BS, Connor KI, Pearson ML, Della Penna RD, Ganiats TG, Demonte RW Jr, Chodosh J, Cui X, Vassar S, Duan N, Lee M. The effect of a disease management intervention on quality and outcomes of dementia care: A randomized, controlled trial. Ann Intern Med. 2006; 145(10):713-26. [PMID: 17116916]

13. Sherman MD, Sautter F, Lyons JA, Manguno-Mire GM, Han X, Perry D, Sullivan G. Mental health needs of cohabitating partners of Vietnam veterans with combat-related PTSD. Psychiatr Serv. 2005;56(9):1150-52. [PMID: 16148334$]$ DOI:10.1176/appi.ps.56.9.1150

14. Goode KT, Haley WE, Roth DL, Ford GR. Predicting longitudinal changes in caregiver physical and mental health: A stress process model. Health Psychol. 1998;17(2):190-98. [PMID: 9548710]

DOI:10.1037/0278-6133.17.2.190

15. Pearlin LI, Mullan JT, Semple SJ, Skaff MM. Caregiving and the stress process: An overview of concepts and their measures. Gerontologist. 1990;30(5):583-94. [PMID: 2276631]

16. Kramer BJ. Gain in the caregiving experience: Where are we? What next? Gerontologist. 1997;37(2):218-32. [PMID: 9127978]

17. Rittman M, Andresen E, Uphold C, Cowper-Ripley D, Hayes J, Damush T, Van Puymbroeck M, Young L. Informal caregivers of veterans post stroke, Final report. Nursing Research Initiative Grant \#05-246. Washington (DC): Health Services Research \& Development Service, Department of Veterans Affairs; 2008.

18. Montgomery RJ, Rowe JM, Kosloski K. Family caregiving. In: Blackburn JA, Dulmus CN, editors. Handbook of gerontology: Evidence-based approaches to theory, practice, and policy. Hoboken (NJ): Wiley; 2007. p. 426-54.

19. Montgomery R, Kwak J. TCARE: Tailored caregiver assessment and referral. Am J Nurs. 2008;108(9 Suppl):54-57. [PMID: 18797229]

20. Bandura A. Self-efficacy: The exercise of control. New York (NY): W. H. Freeman; 1997.

21. Bandura A. Social foundations of thought and action: A social cognitive theory. Englewood Cliffs (NJ): Prentice Hall; 1986.

22. Jordan BK, Marmar CR, Fairbank JA, Schlenger WE, Kulka RA, Hough RL, Weiss DS. Problems in families of male Vietnam veterans with posttraumatic stress disorder. J Consult Clin Psychol. 1992;60(6):916-26.
[PMID: 1460153]

DOI:10.1037/0022-006X.60.6.916

23. Craine MH, Hanks R, Stevens H. Mapping family stress: The application of family adaptation theory to post-traumatic stress disorder. Am J Fam Ther. 1992;20(3):195-203. DOI:10.1080/01926189208250889

24. Kulka RA, Schlenger WE, Fairbank JA. Trauma and the Vietnam War generation: Report of findings from the National Vietnam veteran's readjustment study. New York (NY): Brunner/Mazel; 1990.

25. Calhoun PS, Beckham JC, Bosworth HB. Caregiver burden and psychological distress in partners of veterans with chronic posttraumatic stress disorder. J Trauma Stress. 2002; 15(3):205-12. [PMID: 12092912] DOI:10.1023/A:1015251210928

26. Manguno-Mire G, Sautter F, Lyons J, Myers L, Perry D, Sherman M, Glynn S, Sullivan G. Psychological distress and burden among female partners of combat Veterans with PTSD. J Nerv Ment Dis. 2007;195(2):144-51.

[PMID: 17299302]

DOI:10.1097/01.nmd.0000254755.53549.69

27. Riggs DS, Byrne CA, Weathers FW, Litz BT. The quality of the intimate relationships of male Vietnam veterans: Problems associated with posttraumatic stress disorder. J Trauma Stress. 1998;11(1):87-101. [PMID: 9479678] DOI:10.1023/A:1024409200155

28. Waysman M, Mikulincer M, Solomon Z, Weisenberg M. Secondary traumatization among wives of posttraumatic combat veterans: A family typology. J Fam Psychol. 1993; 7(1):104-18. DOI:10.1037/0893-3200.7.1.104

29. Beckham JC, Lytle BL, Feldman ME. Caregiver burden in partners of Vietnam War veterans with posttraumatic stress disorder. J Consult Clin Psychol. 1996;64(5):1068-72. [PMID: 8916637] DOI:10.1037/0022-006X.64.5.1068

30. Westerink J, Giarratano L. The impact of posttraumatic stress disorder on partners and children of Australian Vietnam veterans. Aust N Z J Psychiatry. 1999;33(6):841-47. [PMID: 10619210$]$ DOI:10.1046/j.1440-1614.1999.00638.x

31. Renshaw KD, Rodrigues CS, Jones DH. Psychological symptoms and marital satisfaction in spouses of Operation Iraqi Freedom veterans: Relationships with spouses' perceptions of veterans' experiences and symptoms. J Fam Psychol. 2008;22(4):586-94. [PMID: 18729672]

DOI:10.1037/0893-3200.22.3.586

32. Evans L, McHugh T, Hopwood M, Watt C. Chronic posttraumatic stress disorder and family functioning of Vietnam veterans and their partners. Aust N Z J Psychiatry. 2003;37(6):765-72. [PMID: 14636394]

33. Marshall AD, Panuzio J, Taft CT. Intimate partner violence among military veterans and active duty servicemen. Clin Psychol Rev. 2005;25(7):862-76. [PMID: 16006025] DOI:10.1016/j.cpr.2005.05.009 
34. Ruscio AM, Weathers FW, King LA, King DW. Male warzone veterans' perceived relationships with their children: The importance of emotional numbing. J Trauma Stress. 2002;15(5):351-57. [PMID: 12392222] DOI:10.1023/A:1020125006371

35. Hoge CW, Auchterlonie JL, Milliken CS. Mental health problems, use of mental health services, and attrition from military service after returning from deployment to Iraq or Afghanistan. JAMA. 2006;295(9):1023-32.

[PMID: 16507803]

36. West AN, Weeks WB. Mental distress among younger veterans before, during, and after the invasion of Iraq. Psychiatr Serv. 2006;57(2):244-48. [PMID: 16452703]

DOI:10.1176/appi.ps.57.2.244

37. Lew HL, Vanderploeg RD, Moore DF, Schwab K, Friedman L, Yesavage J, Keane TM, Warden DL, Sigford BJ. Overlap of mild TBI and mental health conditions in returning OIF/OEF service members and veterans. J Rehabil Res Dev. 2008;45(3):xi-xvi. [PMID: 18629743]

38. Solomon Z, Waysman M, Levy G, Fried B, Mikulincer M, Benbenishty R, Florian V, Bleich A. From front line to home front: A study of secondary traumatization. Fam Process. 1992;31(3):289-302. [PMID: 1451774]

DOI:10.1111/j.1545-5300.1992.00289.x

39. Davidson J, Smith R, Kudler H. Familial psychiatric illness in chronic posttraumatic stress disorder. Compr Psychiatry. 1989;30(4):339-45. [PMID: 2758806] DOI:10.1016/0010-440X(89)90059-X

40. Lyons MA. Living with post-traumatic stress disorder: The wives'/female partners' perspective. J Adv Nurs. 2001;34(1): 69-77. [PMID: 11430608] DOI:10.1046/j.1365-2648.2001.3411732.x

41. Hoppe MJ, Wells EA, Morrison DM, Gilmore MR, Wilsdon A. Using focus groups to discuss sensitive topics with children. Eval Rev. 1995;19(1):102-14. DOI:10.1177/0193841X9501900105

42. Kitzinger J. Introducing focus groups. Br Med J. 1995;311: 299-302.

43. Powell RA, Single HM. Focus groups. Int J Qual Health Care. 1996;8(5):499-504. [PMID: 9117204]

DOI:10.1093/intqhc/8.5.499

44. Lincoln YS, Guba EG. Naturalistic inquiry. Beverly Hills (CA): SAGE Publications; 1985.

45. Kincheloe JL, McLaren P. Rethinking critical theory and qualitative research. In: Denzin NK, Lincoln YS, editors. Handbook of qualitative research. Thousand Oaks (CA): SAGE Publications; 1994. p. 138-57.

46. Holstein JA, Gubrium FJ. The active interview. Thousand Oaks (CA): SAGE Publications; 1995.
47. Lofland J, Lofland L. Analyzing social settings: A guide to qualitative observation and analysis. 3rd ed. Belmont (CA): Wadsworth; 1995.

48. Dekel R, Goldblatt $H$. Is there intergenerational transmission of trauma? The case of combat veterans' children. Am J Orthopsychiatry. 2008;78(3):281-89. [PMID: 19123747] DOI:10.1037/a0013955

49. Center for the Study of Traumatic Stress. Proceedings: Workgroup on intervention with combat injured families. Bethesda (MD): Center for the Study of Traumatic Stress; 2007.

50. Reich J, Lyons M, Cai B. Familial vulnerability factors to post-traumatic stress disorder in male military veterans. Acta Psychiatr Scand.1996;93(2):105-12. [PMID: 8686479] DOI:10.1111/j.1600-0447.1996.tb09810.x

51. Andresen EM. Criteria for assessing the tools of disability outcomes research. Arch Phys Med Rehabil. 2000;81(12 Suppl 2):S15-20. [PMID: 11128900] DOI:10.1053/apmr.2000.20619

52. Lohr KN, Aaronson NK, Alonso J, Burnam MA, Patrick DL, Perrin EB, Roberts JS. Evaluating quality-of-life and health status instruments: Development of scientific review criteria. Clin Ther. 1996;18(5):979-92. [PMID: 8930436] DOI:10.1016/S0149-2918(96)80054-3

53. Mokkink LB, Terwee CB, Stratford PW, Alonso J, Patrick DL, Riphagen I, Knol DL, Bouter LM, De Vet HC. Evaluation of the methodological quality of systematic reviews of health status measurement instruments. Qual Life Res. 2009;18(3):313-33. [PMID: 19238586$]$

DOI:10.1007/s11136-009-9451-9

54. Warren CA. Qualitative interviewing. In: Gubrium JF, Holstein JA, editors. Handbook of interview research: Context \& method. Thousand Oaks (CA): SAGE Publications; 2002. p. 83-102.

Submitted for publication April 17, 2009. Accepted in revised form June 29, 2010.

This article and any supplementary material should be cited as follows:

Hayes J, Wakefield B, Andresen EM, Scherrer J, Traylor L, Wiegmann P, Demark T, DeSouza C. Identification of domains and measures for assessment battery to examine well-being of spouses of OIF/OEF veterans with PTSD. J Rehabil Res Dev. 2010;47(9):825-40.

DOI:10.1682/JRRD.2009.04.0049

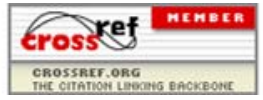

